\title{
RöKo goes \\ International
}

Die neue Programmlinie „RöKo international“ bündelt alle ausländischen Beiträge auf dem Deutschen Röntgenkongress.

Premiere auf dem 96. Deutschen Röntgenkongress: Erstmals werden alle internationalen Vorträge unter dem Label „RöKo international“ zu einem einheitlichen Programm zusammengeführt.

„RöKo International“ ist die Fortführung der jahrelangen guten Zusammenarbeit mit unseren Kooperationspartnern aus Asien und gemeinsamer Projekte mit anderen europäischen Gesellschaften.

Nun bekommen die traditionellen Auftritte unserer ausländischen Gäste eine eigene Plattform und damit die Möglichkeit bestehende Kontakte zu stärken und neue zu knüpfen. Die Sitzungen finden an Mittwoch, den 13.05.2015 und Donnerstag, den 14.05.2015 statt und sind eine Kombination aus herausragenden Referenten und grundlegende Themen der Radiologie. Die Vorträge werden in englischer Sprache gehalten und richten sich an das Kongresspublikum vom Weiterbildungsassistenten bis zum erfahrenen Facharzt.

Kongresspräsident und Geschäftsstellenteam freuen sich über Ihre Teilnahme! Das Programm 2015 werden Sie in Kürze auf www.roentgenkongress.de einsehen können. 